\title{
Prevalence and pathological lesions of bovine tuberculosis assessment through routine procedures of meat inspection in infected cattle in Karachi metropolitan corporation abattoirs
}

\author{
Mujeeb-ur-Rahman Memon ${ }^{1 *}$, Abdul Latif Bhutto ${ }^{1}$, Muhammad \\ Ghiasuddin Shah ${ }^{1}$, Pershotam Khatri ${ }^{1}$, JahanAra Baloch ${ }^{2}$, Riaz Ahmed \\ Leghari $^{1}$ and Saeed Ahmed Soomro ${ }^{1}$ \\ 1. Faculty of Animal Husbandry and Veterinary Sciences, Sindh Agriculture University Tandojam-Pakistan \\ 2. Central Veterinary Diagnostic Laboratory, Tandojam-Pakistan \\ *Corresponding author's email: drmujeebsau@gmail.com \\ Citation \\ Mujeeb-Ur-Rehman Memon, Abdul Latif Bhutto, Muhammad Ghiasuddin Shah, Pershotam Khatri, Jahan \\ Ara Baloch, Riaz Ahmed Leghari and Saeed Ahmed Soomro. Prevalence and pathological lesions of bovine \\ tuberculosis assessment through routine procedures of meat inspection in infected cattle in Karachi metropolitan \\ corporation abattoirs . Pure and Applied Biology. Vol. 8, Issue 3, pp1909-1918. \\ http://dx.doi.org/10.19045/bspab.2019.80134
}

Received: 22/05/2019 $\quad$ Revised: 15/07/2019 $\quad$ Accepted: 17/07/2019 $\quad$ Online First: 19/07/2019

\section{Abstract}

Bovine tuberculosis (bTB) caused by Mycobacterium bovis is one of the most important zoonotic disease that poses huge economic losses in livestock population worldwide. A cross sectional study was therefore designed to investigate its prevalence and efficacy of meat inspection procedures for its detection in slaughtered cattle at two abattoirs of Karachi. A total 2000 were examined during March 2015 to September 2016 in which 943 animals were found suspected for bTB and necropsied from which 1170 organ samples were collected. The data collected was analyzed using Chi-square test. Results of regular and complete examination revealed that $8.12 \%$ organ samples had positive lesions of tuberculosis. The highest frequency of lesions were observed in lungs and its associated lymphnodes (64\%) i.e. mediastinal lymphnodes $(27 \%)$, tracheobronchial lymphnodes $(26 \%)$, lungs $(11 \%)$ respectively. There was a significant difference $(P<0.05)$ in prevalence of bTB amongst sex of cattle. Females were found at high risk of bTB. It was concluded from the results that however bTB is highly prevalent in cattle and sensitivity of inspection protocols may influence reporting positive cases. Thus it is suggested that more advanced and sensitive methods should be used for screening of tuberculosis in cattle population.

Keywords: Bovine tuberculosis; Meat inspection; Prevalence and Pathological lesions

Introduction

Tuberculosis (TB) is considered to be the second most widespread zoonotic disease around the world, killing around 8.6 million people yearly and can cause infection in the groups of animals that leads to huge economic loss [1]. It is caused by inhaling airborne droplet nuclei containing viable organisms, characterized by slowly progressive signs of malaise, anorexia, weight loss, fever and night sweats and frequently presented with 
chronic cough and blood-streaked sputum in human[2,3].

Due to slow progressive development of clinical signs of Mycobacterium bovis infection in susceptible cattle, it is difficult to diagnose disease at early stage with routine examinations. In advanced stages most clinical signs such as emaciation, lethargy, weakness, anorexia, lowgrade fever and pneumonia with a chronic, moist cough and enlarged lymph nodes become apparent. Once the outbreak bTB occurs in cattle, leads to heavy economic losses due to reduced milk yield and carcass value [4].

The disease is usually transmitted through direct contact with infected animals, ingestion of infected animal products and many ways including housing, feeding and colostrums/milk and watering of infected and non-infected animals. BTB commonly affects older animals and mainly restricted to the respiratory system. It's spread from person to person by respiratory aerosol and its primary site of infection is the lung and resides chiefly in the macrophage. Most of the transmission is occurring by the coughing of smear-positive people [2]. The affected animals show progressive weight loss, tubercle (granuloma) formation primarily in the lungs and occasionally in other tissues. The disease may also engross other tissues, including the liver, intestines, uterus and testes; however, central nervous system (CNS) involvement has not been reported $[5,6]$.

Studies suggest that raw or improperly cooked meat is potential source of transmitting $M$. bovis infection from animal to human. M. bovis does not transmit from immune competent person to person, but its sporadic transmission from infected human population to healthy population if it is alcoholics or HIVinfected. Vertical transmission M.bovis infection from human through erosols or urine is very rare [7].

The lung is primarily hosted organ causes pulmonary tuberculosis but the second phase of tuberculosis infects the intestines, meninges, bones, joints, lymph glands, skin, kidneys and other tissues of the body $[8,9]$.

M. Bovis can acutely infect the cattle and rapidly spread in various tissues of its body but the most prominent lesions appear in its host tissue in lymphatic system of head and thorax region. Lymphnodes in lungs, intestines, liver, spleen, pleura and peritoneum may also be infected. $M$. bovis produces latent infection in host tissue and protect itself to survive for longer duration from months to several years in animal body causing a chronic disease, without any clinical signs [10, 11]. Keeping in view the zoonotic importance and threat of severe economic losses in livestock, present study was designed to investigate prevalence bovine $\mathrm{TB}$ and assess the efficiency of meat inspection protocols followed for its diagnosis in dairy cattle slaughtered in abattoirs of Karachi..

\section{Plan of work}

All animals used in the current study belonged to slaughter house, therefore, there was no any need of approval of this study from ethics committee of the concerned institute.

To achieve the objectives of study conducted during March 2015 to September 2016, two abattoirs, one situated at City Abattoir Cattle Colony in Landhi and second at New Karachi were selected. Total 943 cattle including 700 adult males and 243 adult females were selected for study. Physical examination of all cattle for body condition scores BCS and any external lesion was performed before slaughtering as per procedure described by [12]. Breed, age, sex, body temperature, pulse and respiratory rate were also recorded. All animals were examined for presence any nasal discharge, any swelling in regional lymph nodes and visible mucous membranes. After completion of physical examination animals were allowed for slaughtering. Post-slaughtering, the cattle carcasses were subjected to routine meat inspection for any visible lesion of 
bTB on muscle surface of different body regions.

All visceral organs including lungs, intestine, kidney, liver and lymphnodes were collected examined for TB with the permission of authorities of abattoirs.

\section{Collection and processing of samples}

Whole Blood was collected during slaughtering of an animal while only suspected tissues of tuberculosis were collected for Acid Fast Test. A total of 943 slaughtered animals were necropsies, from which 1170 organ samples including lungs (338), liver (257), lymphnodes (313), spleen (110) and intestines (152) were collected (Plate 1). Tissues from organs those have lesions were processed for culture and histopathology for isolations and identifications of Mycobacterium in Central Veterinary Diagnostic Centre Karachi. Tissue samples were examined for evidence of lesions, such as granulomatous, cysts and fibrosis of tuberculosis in bovines. Nine organs, tissue samples were collected from the slaughterhouse of Karachi every week for 130 weeks. The ages of animals ranged from 4-7 years. Lymphnodes from the respiratory tract, lungs, intestine and liver tissue, lymphnodes from gastrointestinal tract and pus or caseious material from open tuberculosis cavities were collected, the specimen most frequently submitted for laboratory examination. They were usually selected for inspection in slaughterhouses when macroscopic lesions suggestive of tuberculosis were detected. The animals were examined just before slaughter to record body condition; as good, fair, or poor, the age; an adult or young and sex; male or female. About 5 $\mathrm{ml}$ of whole blood was collected.

Samples were labeled and transported on ice in a cooler to the laboratory were stored in a refrigerator for not more than three days until processing. Individual information on an animal such as age, sex, breed and body condition scores was taken during blood collection. Slaughtered animals were examined, at post mortem for TB lesions. Visceral organs and lymphnode were inspected through careful visual palpation and incision procedures for nodules and granulomatous lesions as described by $[13,14]$. Tissue samples were collected aseptically from an animal with suspected lesions of TB in sterile screwcapped containers and transported on ice box to the laboratory where they were kept frozen until processed.

Enlarged and consolidated lung with fibrin deposition is shown in (Plate 2), whereas enlarged spleen is visible in (Plate 3) severely necropsed.

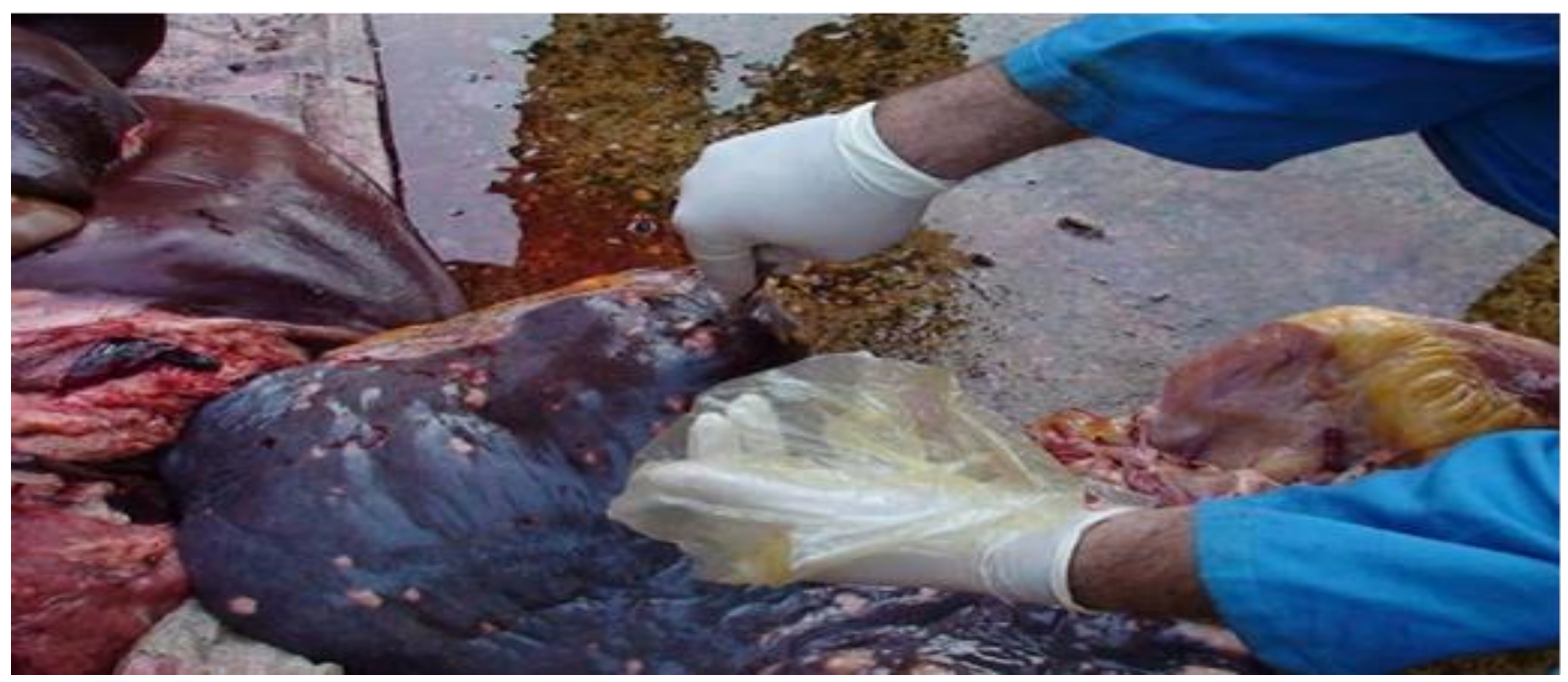

Plate 1. Sample collection from a suspected tuberculosis liver 


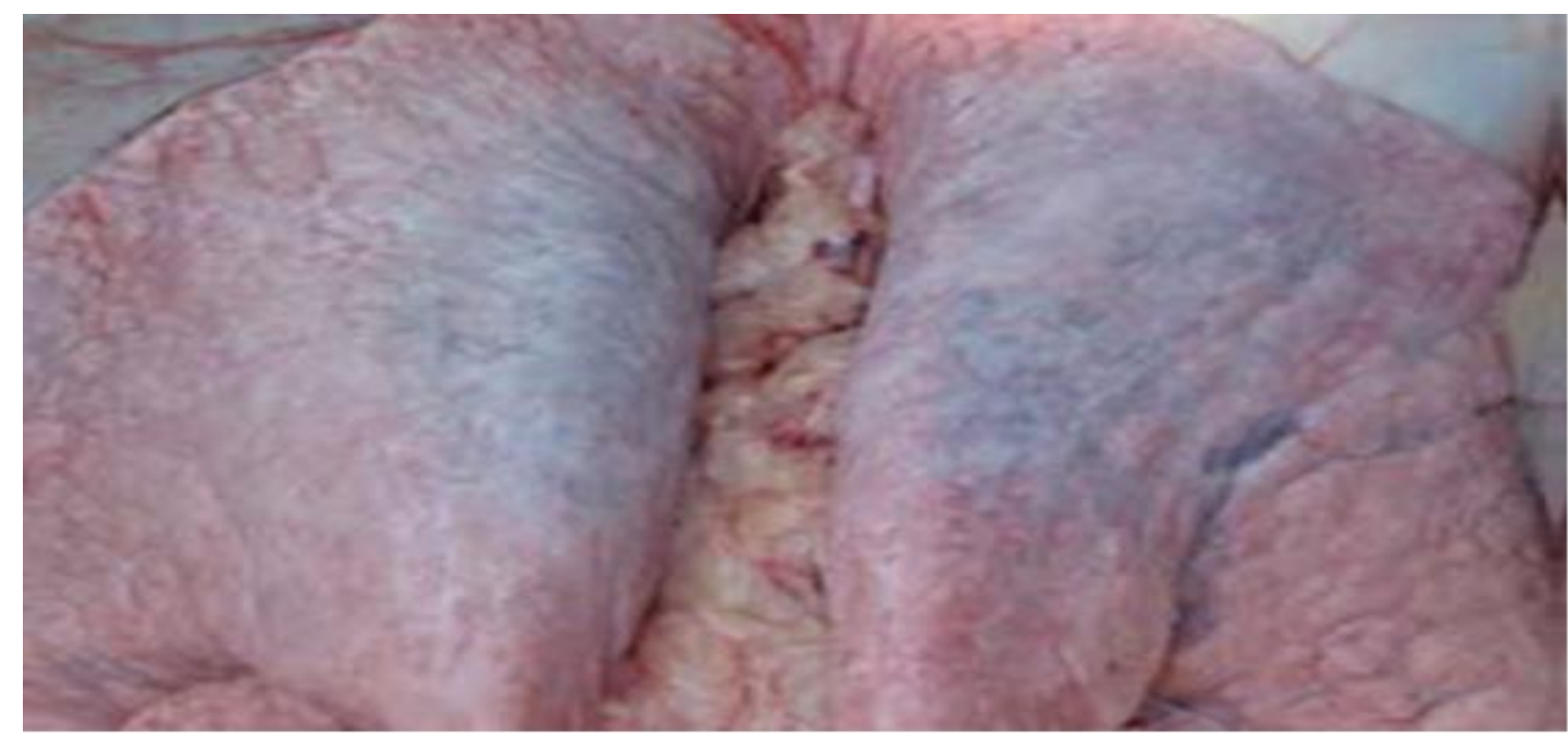

Plate 2. Congested and consolidated lung at the time of necropsy from a tuberculin +ve cow

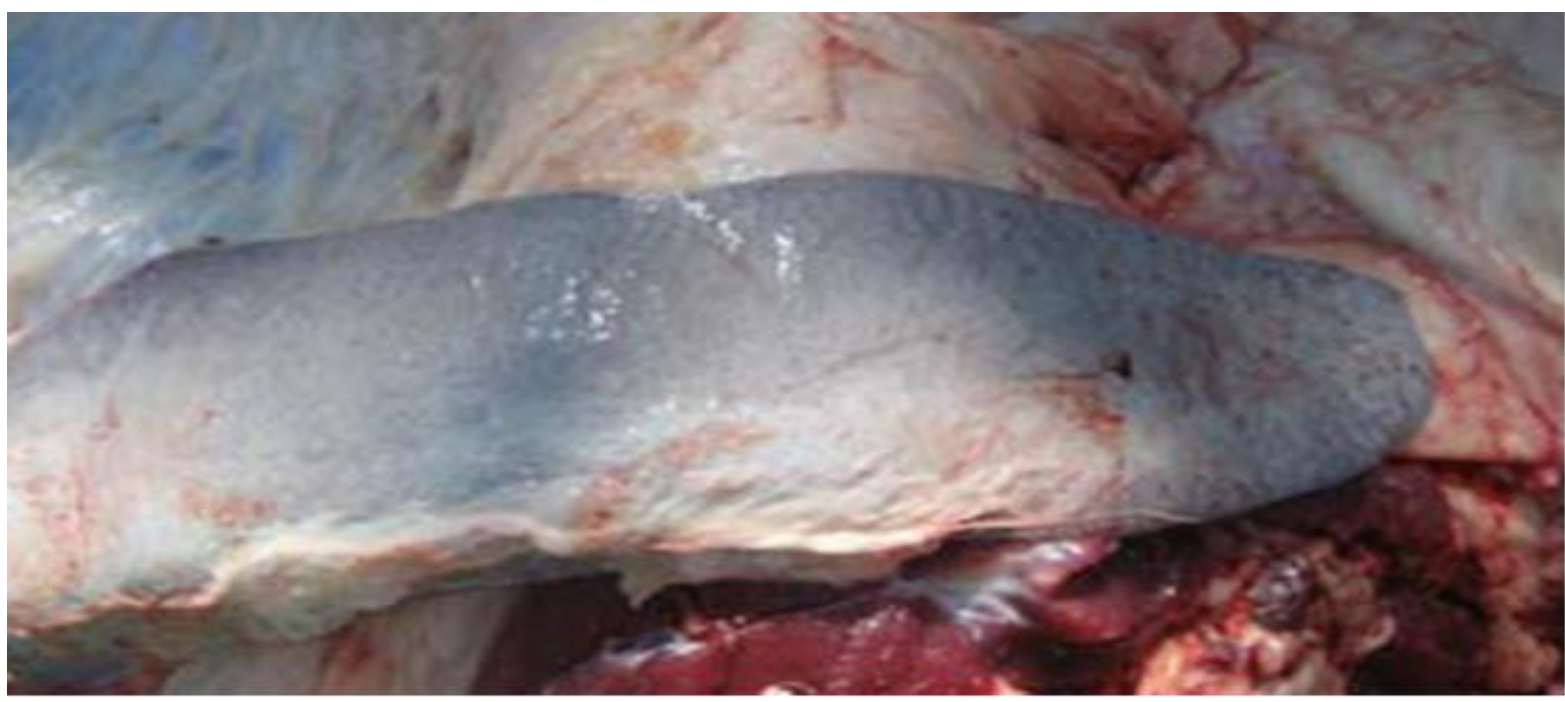

Plate 3. Enlarged Spleen obtained from a tuberculin +ve cow

Detailed examination of carcass and visceral organs

Detailed examination of the carcasses and visceral organ samples was performed according to method described by $[16,17]$. During the inspection, the emphasis was given to positive organs and lymphnodes for the presence of suspected bTB lesions. The cut surfaces were examined under a bright light for the presence of an abscess, cheesy mass, and tubercles by Corner [13]. Those animals were classified as positive for bTB whose organs and lymphnodes showed gross lesion indicative of tuberculosis.

\section{Data collection and analysis}

The data collected was analyzed with SPSS 16.0 version. Significant difference was recorded at $\mathrm{p}$-value $(\mathrm{P}<0.05)$.

\section{Results}

The results of regular and detailed inspection of carcasses are shown in (Table 1). And results indicates that overall 95/1170 (8.12\%) samples were found positive on detailed meat inspection. From these 95 positive 
samples only 15 were reported as positive on regular inspection whereas, remaining 80 were reported as negative. This revealed $84.21 \%$ probability missing in TB lesions during routine abattoir inspection.

Prevalence of bTB in different breeds of cattle is shown in (Table 2). Highest prevalence percent was recorded in Thari cattle which is 35.49 percent followed by Nili Ravi 2.86 percent, Red Sindhi 1.54 percent and Kundhi which is 0.67 percent, whereas Sahiwal was found free from infection. The Statistical analysis showed highly significant $(\mathrm{P}<0.05)$ difference in prevalence rate of bTB amongst breeds.
Results of prevalence of bovine tuberculosis in cattle of different sex, age and body conformation score (BCS) are depicted in (Table 3). Results of study revealed that female cattle were susceptible to $M$. bovis infection with $18.52 \%$ prevalence of bTB. Statistical analysis showed highly significant difference $(\mathrm{P}<0.05)$ amongst female and male cattle. Cattle in age group $>6$ years were more susceptible to infection; however there was no significant difference between the age groups. Animal with severe emaciation condition had highest prevalence of bTB.

Table 1. Comparison of the results of a regular and complete inspection

\begin{tabular}{|c|c|c|c|}
\hline \multirow{2}{*}{ Regular meat inspection } & \multicolumn{2}{|c|}{ complete organs inspection } & \multirow{2}{*}{ Total } \\
\cline { 2 - 3 } & Positive & Negative & \\
\hline Positive & $15(15.79 \%)$ & $0(0.00 \%)$ & $15(1.28 \%)$ \\
\hline Negative & $80(84.21 \%)$ & $1075(100.00 \%)$ & $1155(0.99 \%)$ \\
\hline Total & $95(100.00 \%)$ & $1075(100.00 \%)$ & $1170(8.12 \%)$ \\
\hline
\end{tabular}

Sensitivity $=15.79 \%$

Table 2 Prevalence of bovine tuberculosis in different breeds of cattle

\begin{tabular}{|c|c|c|c|c|c|}
\hline Breed & No. of animals examined & Positive & Percentage & Chi square & p-value \\
\hline Kundhi & 734 & 5 & 0.67 & \multirow{6}{*}{94.90} & \multirow{6}{*}{0.000} \\
\hline Nili-Ravi & 105 & 3 & 2.86 & & \\
\hline Red Sindhi & 65 & 1 & 1.54 & & \\
\hline Sahiwal & 22 & 0 & 0 & & \\
\hline Tharri & 17 & 6 & 35.49 & & \\
\hline Total & 943 & 15 & 1.59 & & \\
\hline
\end{tabular}

Table 3. Prevalence of bovine tuberculosis in cattle of different sex, age, and body conformation score (BCS)

\begin{tabular}{|c|c|c|c|c|c|}
\hline Variable & $\begin{array}{c}\text { No. of animals } \\
\text { examined }\end{array}$ & Positive & Percentage & Chi-square & p-value \\
\hline Sex & 700 & & & & \\
Male & 243 & 45 & 0.86 & 91.74 & 0.0000 \\
Female & 35 & & & & \\
Age & 908 & 48.52 & 5.57 & 0.62 & 0.4310 \\
>4years & & & & & \\
>6 years & 665 & 41 & 6.16 & & \\
Body conformation & 125 & 7 & 5.60 & & \\
score & 93 & 2 & 2.15 & 2.77 & 0.4292 \\
Severe Emaciation & 35 & 1 & 2.86 & & \\
Thin condition & & & \\
Moderate condition & & & & \\
Heavy condition & &
\end{tabular}


Distribution of bTB lesions in different organs of slaughter cattle is given in (Figure $1)$. The data indicates that lymph nodes in organs of upper respiratory tract were more predominantly infected with M.bovis. Amongst the organs examined for lesions of bTB, the highest number were recorded in mediastinal, 27.0 percent followed by tracheobronchial i.e. 26.0 percent 11.0 percent lungs, 9.0 percent medialretropharyngeal and mesenteric lymphnodes each, 5.0 percent liver and prefemoral lymphnode each and 4.0 percent mandibular and prescapular lymphnodes were having positive lesions of bTB (Plate 4).

Frequency of tuberculosis lesions in different organs of cattle examined are shown in (Figure 2). The results indicated that frequency of lesion is highest in tracheobronchial lymph node $30.0 \%$ followed by mediastinal lymphnode i.e. $26.0 \%$, lungs $11.0 \%$, $9.0 \%$ mesenteric lymphnode, $8.0 \%$ medialretropharyngeal lymphnode, $6.0 \%$ prescapular lymphnode, $4.0 \%$ mandibular lymphnode and $3.0 \%$ each prefemoral and liver.

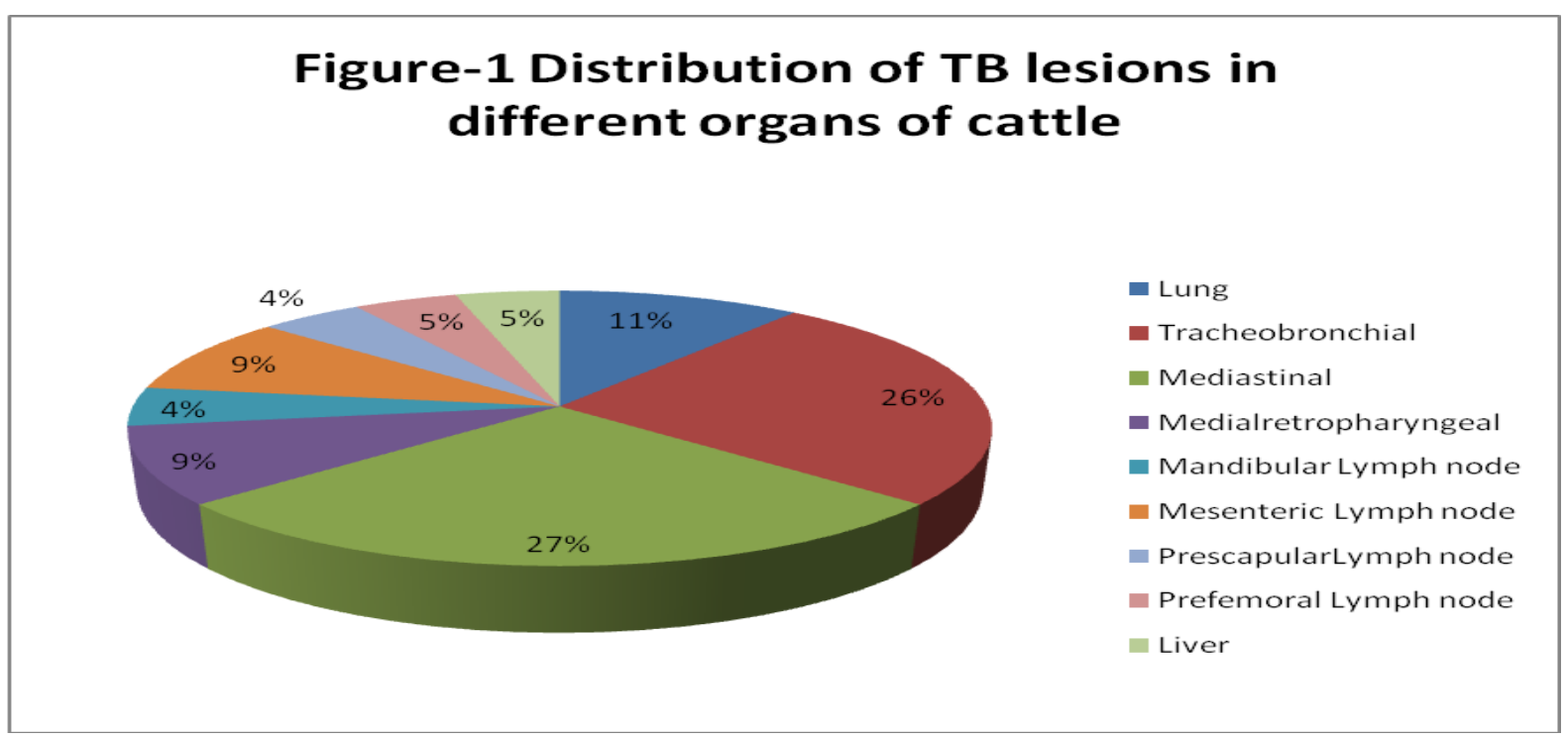

Figure 1. Distribution of TB lesions in different organs of cattle

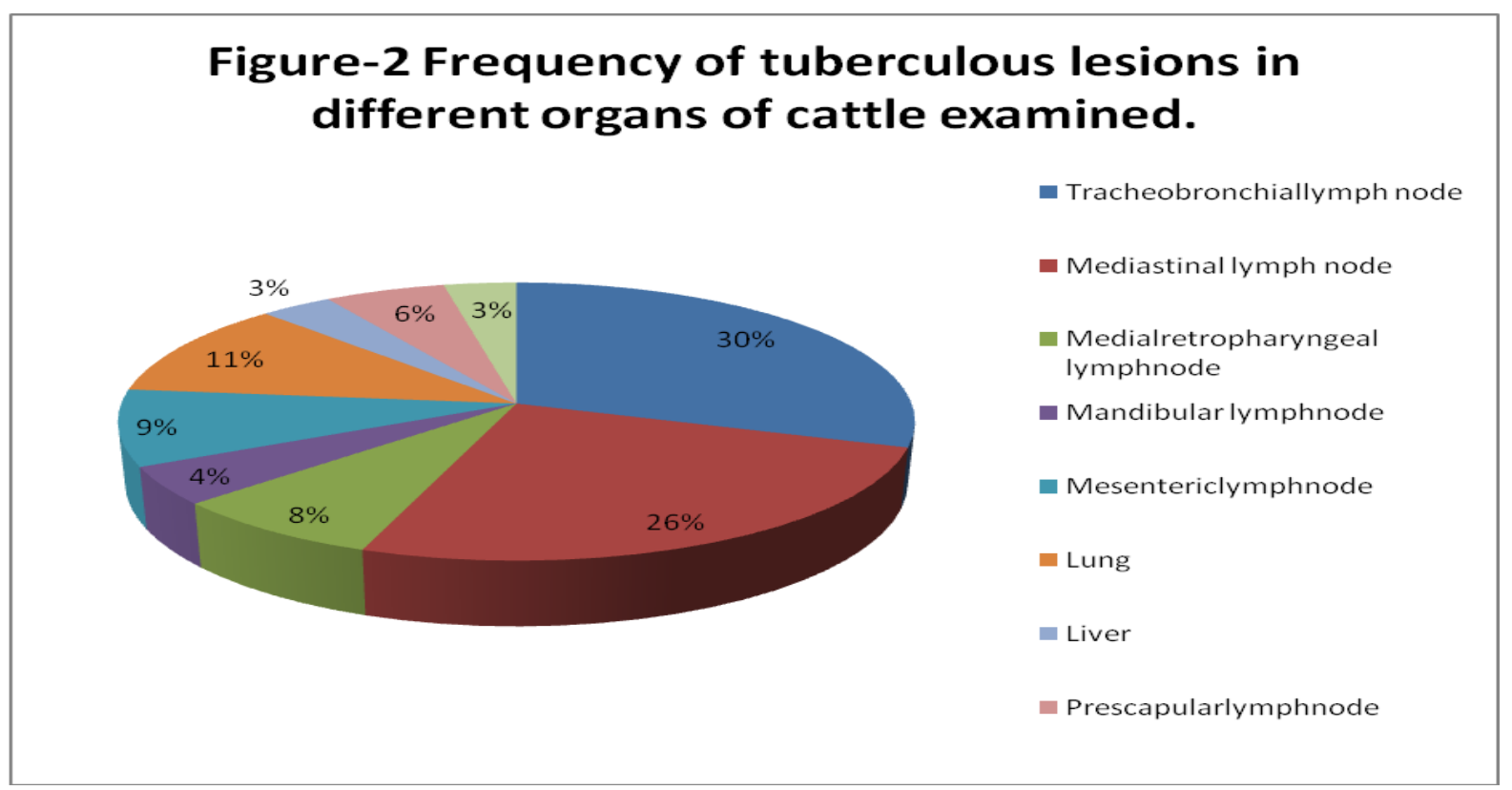

Figure 2. Frequency of tuberculous lesions in different organs of cattle examined 

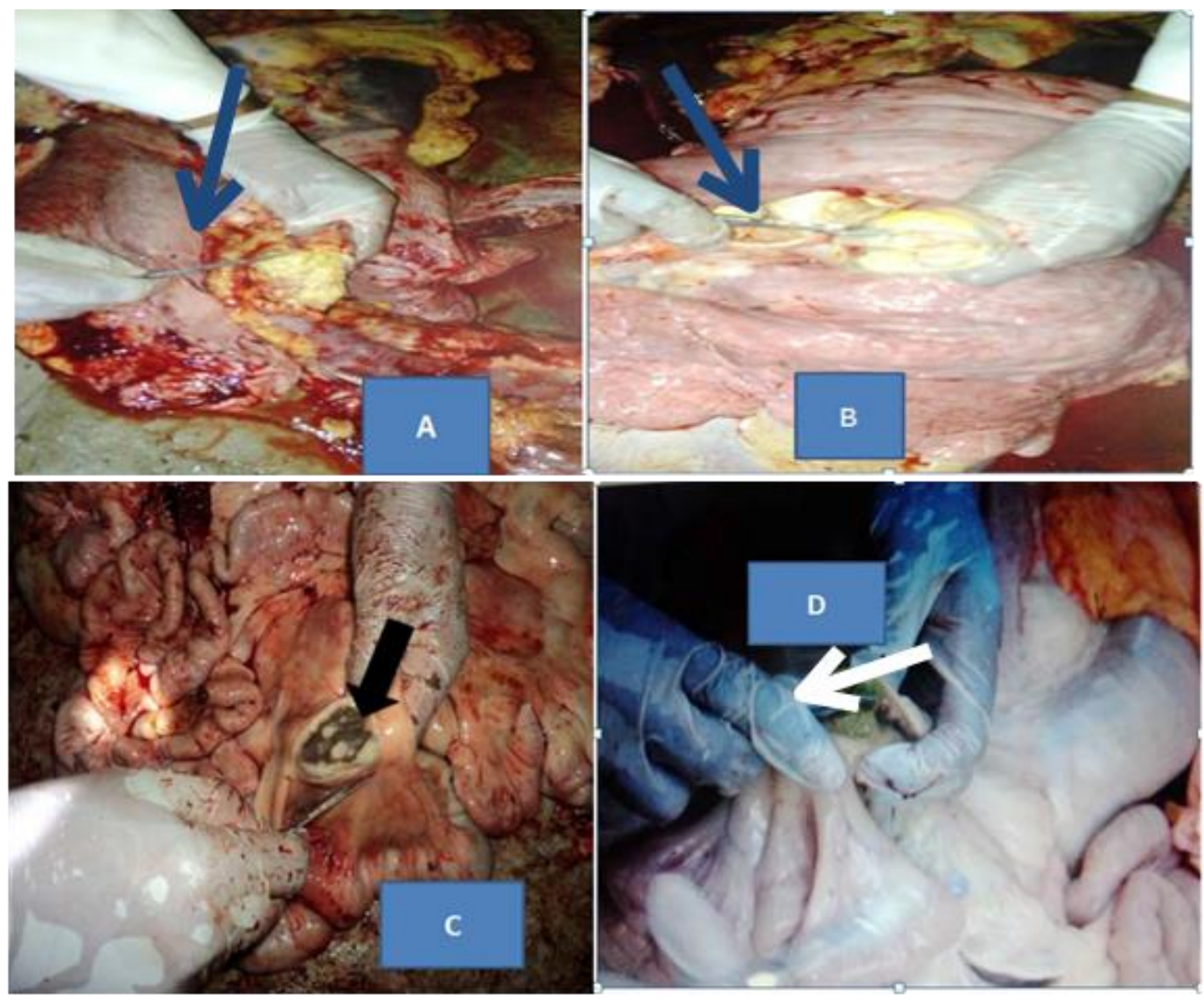

Plate 4. Typical TB lesions of cattle slaughter in Karachi Metropolitan Corporation (KMC) abattoirs $A=$ granomulatous lesions from the mediastinum, $B=$ caseous and granomulatous necrosis in lung and $C \& D=$ calcified and granomulatous lesions in mesenteric lymph nodes

\section{Discussion}

Bovine tuberculosis is caused by Mycobacterium bovis. It is one the important recognized zoonotic risk for the human population in the areas where peoples are rearing animals for their livelihood and they have frequent contact the animals. $M$. bovis may spread not only from diseased animals to human in their contact but from infected animals to healthy animals. Because of high risk of transmission of disease organism and suspected losses due to mortality, morbidity and loss of production present study was carried out. Cattles brought at abattoir for slaughter in Karachi were used in this study. Following the procedure of preslaughter examination of animals and then examination carcass and visceral organs the data were collected for presence of lesions of bTB to calculate the prevalence of tuberculosis in cattle. In present study it was observed that $8.12 \%$ of cattle brought for slaughtering in both metropolitan abattoirs of Karachi were having lesion of tuberculosis. The finding suggested that there is great risk of disease transmission within animal population as well human. The examination protocols were followed as described by other researchers and the finding of present study were in agreement with those of previous studies 
done with similar diagnostic methods[1820]. Prevalence of bTB in cattle breeds of Pakistan was comparatively lower than that reported in different countries and breed of cattle [16, 21-23].

Difference in prevalence of bTB amongst different breeds can be attributed to its genetic characteristic. It may be lower in animal with resistance of bTB for example Zebu cattle which is relatively resistant to bTB. Variability it appearance of gross lesion in cattle infected with Mycobacterium bovis have been reported. Some breeds do not show gross lesions of tuberculosis in their tissues examined at slaughter [24].

There are other methods of isolation $M$. bovis from infected tissues and lymphnodes, such as culture of tissue and lymphnodes and lungs with no visible lesions [13].

Sensitivity of detection methods influences the diagnosis of disease. The routine physical examination of carcass for presence of tuberculosis lesions is commonly used in our country. In present study sensitivity of routine inspection was compared with the detailed examination. Results showed that routine abattoir inspection was less sensitive. It could detect tuberculosis only $15.79 \%$ Kappa $=0.14$ whereas $84.21 \%$ were negative which were otherwise found positive when detailed examination was performed. Several factor effects on detection of lesion such as examination of less number of samples and tiny un visible lesion and site of infection [25].Several studies have reported that the prevalence of tuberculosis infection increases with enhanced meat inspection procedures such as multiple slicing of organs and lymph nodes[13, 24]. Detailed necropsy procedures for detection of tuberculosis have been described [13, 20]. They considered this method as satisfactory because almost $84 \%$ of all lesion of tuberculosis can be observed. In present study $64.0 \%$ of gross tuberculosis lesions were recorded in lungs and its associated lymphnodes. Such findings are in consistent with those reported in Ethiopia [26, 27]. They found 70 and $70.7 \%$ TB lesions in lungs and associated lymphnodes, respectively. Thus results of present study differs from Milianosuazo, who found in a study conducted in Mexico distribution of TB lesion were predominantly present in retropharyngeal lymphnodes that was $49.2 \%$ of lesion found in all body[28].

Research studies conducted by Corner found that up to $95 \%$ cattle shown visible TB lesions in lungs and associated lymph nodes which suggest that tuberculosis infection is more likely to spread through infected droplets in aerosol inhaled by healthy animals [13]. Therefore examination of lungs should be more focused for diagnosis of tuberculosis lesions. Infection may spread through ingestion as lesions are also found in mesenteric lymph nodes [29]. In present study complete meat inspection could detect $84.21 \%$ positive tuberculosis carcasses which otherwise reported as negative on routine examination. This missing in detection of lesions in carcass can be attributed to the presence of very minute or single lesion present in infected tissue. In present study $72 \%$ of animals had single lesion. These results are supported by the findings of previous studies conducted by [13, 20, 27]. They also emphasize the possibility of missing a tuberculosis carcass during routine inspection procedures. It is therefore suggested that chances of failure in detection of single lesion during abattoir inspection could be overcome by following complete necropsy otherwise false negative reports may lead to increased risk of disease spread due to less focusing on its control measures.

Significantly higher prevalence of tuberculosis was recorded in present study. This difference between both sexes is considered due to the physiological stress of longer lactation, pregnancy and parturition which $[20,28]$. Level of body's 
immune response of animal body may help combating any infection and protect it from disease development. Due to many factors animal body becomes weak and its local and systemic immune system is down regulated which make it prone to infection. In current study the result revealed that animals which were highly emaciated and had low BCS were significantly higher prevalence of disease. Radostits describes that animals with good BCS have a relatively good immunological response to the infectious agent than animals with medium BCS [29]. Similarly old age animals were also found at high risk of tuberculosis as appeared in the results of present study. The young animals have greater potential to resist the deleterious effects of infection and development of disease. Since the tuberculosis infection remain as latent for longer duration from months to years as soon as bodies immue system down regulate because of old age body, provides chance to latent infection to activate and develop disease and show its clinical signs.

\section{Authors' contributions}

Conceived and designed the project: MR Memon, Performed the experiment: MR Memon, Analyzed the data while: JA Baloch \& AL Bhutto, Contributed in materials, tools and field supervision: MG Shah, P Khatri \& RA Leghari, helped in data analysis and proof reading of manuscript: SA Soomro \& AL Bhutto.

\section{Acknowledgments}

The authors also acknowledge to the Central Veterinary Diagnostic Laboratory, Tandojam-Pakistan, dairy farms and Abattoir staff for their assistance and cooperation.

\section{References}

1. Spavieri J, Allmendinger A, Kaiser M, Casey R, Hingley-Wilson, Lalvani S, Guiry AMD, Blunden \&Tasdemir GD (2010). Antimycobacterial, antiprotozoal and cytotoxic potential of twenty-one brown algae (phaeophyceae) from British and Irish waters. Phytotherapy Res 24: 17241729.

2. Vikas Saket K, Kachhi R \& Singh $P$ (2017). Tuberculosis in Animals and Humans: Evolution of Diagnostics and Therapy. Asian J of Ani and Vet Advan 12: 177.

3. Chesnutt MS, Murray J \& Prendergast T (2008). Pulmonary disorders. Current Medical Diagnosis and Treatment 47: 203.

4. Gumi B, Schelling E, Berg S, Firdessa R, Erenso G, Mekonnen W, Hailu E, Melese E, Hussein J, Aseffa A \& Zinsstag J (2012). Zoonotic transmission of tuberculosis between pastoralists and their livestock in South-East Ethiopia. Eco Health 9(2): 139-149.

5. Hulnick D, Megibow A, Naidich D, Hilton S, Cho K \& Balthazar E (1985). Abdominal tuberculosis: CT evaluation. Radiol 157: 199-204.

6. Sherlock S \& Dooley J (2008). Diseases of the liver and biliary system. John Wiley \& Sons.

7. Tsegaye A, Aseffa A, Mache A, Mengistu Y \& Berg S (2010). Conventional and Molecular Epidemiology of bovine tuberculosis in dairy farms in Addis Ababa City, the capital of Ethiopia. J of App Res in Vet Med 8: 143-151.

8. Sharma S \& Mohan A (2004). Extra pulmonary tuberculosis. Indian $J$ of Med Res 120: 316-353.

9. Tuli S (2004). Tuberculosis of the skeletal system: bones, joints, spine and bursalsheaths. Jaypee Brothers Publishers.

10. Jolles AE, Cooper DV \& Levin SA (2005).Hidden effects of chronic tuberculosis in African buffalo. Ecol 86: 2358-2364.

11. Pollock J, Welsh M \& McNair J (2005). Immune responses in bovine tuberculosis: towards new strategies for the diagnosis and control of disease. Vet Immun and Immunopath 108: 37-43.

12. Radostits OM, Gay C, Hinchcliff KW \& Constable PD (2007). A textbook of the diseases of cattle, horses, sheep, 
pigs and goats. Veterinary Medicine. 10th ed. London: Saunders, pp 15481551.

13. Corner LA (1994). Postmortem diagnosis of $M$. bovis infection in cattle. Vet Microbiol 1(40): 53-63.

14. World Health Organization (WHO) (2011). Emerging and other Communicable Diseases, Surveillance and Control, pp 3-4.

15. Flynn, R.J, Mannion C, Golden O, Hacariz O \& Mulcahy G (2007). Experimental Fasciola hepatica Infection Alters Responses to Tests Used for Diagnosis of Bovine Tuberculosis. Infect Immun 75(3): 1373-1381.

16. Ameni G, Aseffa A, Engers H, Young $D$, Gordon S, Hewinson G \& Vordermeier M (2007). High Prevalence and Increased Severity of Pathology of Bovine Tuberculosis in Holsteins Compared to Zebu Breeds underField Cattle Husbandry in Central Ethiopia. Clin Vaccine Immunol 13561361.

17. Biffa D, Bogale A \& Skjerve E (2010). Diagnostic efficiency of abattoir meat Inspection service in Ethiopia to detect carcasses infected with Mycobacterium bovis: Implications for public health. BMC Public Health 10: 462.

18. Regassa A, Tassew A, Amenu K, Megersa B, Abunna F, Mekibib B, Marcotty T \& Ameni G (2010). A cross-sectiona lstudy on bovine tuberculosis in Hawassa townand its surroundings, Southern Ethiopia. Trop Anim Health Prod 42: 915-920.188.

19. Ameni G \& Wudie A (2003). Preliminary study on bovine tuberculosis in Nazareth municipality abattoir of central Ethiopia. Bull. Anl Health Prod Afr 51: 125-132.

20. Teklu A, Asseged B, Yimer E, Gebeyehu M \& Woldesenbet Z (2004). Tuberculous lesions not detected by routine abattoir inspection: the experience of the Hossana municipal abattoir, Southern Ethiopia. Rev Sci Tech off Inter Epiz 23(3): 957-964.

21. Ameni G \&Roger F (1998). Study on the epidemiology of bovine tuberculosis in (dairy farms Debrezeit and Ziway, Ethiopia). In proceedings of $12^{\text {th }}$ conference of Ethiopian veterinary association.

22. KirosT (1998). Epidemiology and Zoonotic importance of bovine tuberculosis in a selected site of Eastern Shoa, Ethiopia, Faculty of Veterinary Medicine, Addis Ababa University and the Free University of Berlin, MSC thesis.

23. Pritchard DG (1988). A century of bovine tuberculosis1. Conquest and controversy. J Comp Pathol 99: 357387.

24. Whiple LD, Boline AC \& Miller MJ (1996). Distribution of lesions in cattle infected with Mycobacterium bovis. $J$ Vet Diagn Invest 8: 351-354.

25. Corner LA, Melville L, McCubbin K, Small KJ, Mc-Cormick BS, Wood PR \& Rothel JS (1990): Efficiency of inspection procedures for the detection of tuberculous lesions in cattle. Aus Vet $J$ 67: 389-392.

26. Firdissa R (2006). tuberculosis in and aroundSulultatown, North Shoazone of Oromia, Addis AbabaUniversity, Faculty of Veterinary Medicine, DVM thesis.

27. Nesredin H (2006).Cross section study of BTB in Butajira municipality abattoir, Southern Ethiopia, Addis Ababa University, Faculty of Veterinary Medicine, DVM thesis.

28. Miliano-suazo F, Salmar MD, Ramirez C, Payeur JB, Rhyan SC \& Santillan M (2000). Identification of animals in Mexico. Am J Vet Res 61: 86-7.

29. Radostits OM, Blood DC \& Gay CC (1994).Veterinary Medicine. A textbook of the diseases of cattle, sheep, pigs, goats and horses. $9^{\text {th }}$ Ed. London. BallierTindals, pp 830-838. 